\title{
Do National Frameworks Help in Local Policy Development? Lessons from Yukon about the Evergreen Child and Youth Mental Health Framework
}

\author{
Gillian Mulvale \\ McMaster University \\ Stanley Kutcher \\ Dalhousie University \\ Glen Randall, Patricia Wakefield, Christopher Longo, \\ Julia Abelson, and Judi Winkup \\ McMaster University \\ Marie Fast \\ Yukon Government
}

\begin{abstract}
National frameworks are often put forward as a tool for local policy development, but little is known about their effectiveness. In this case study, the usefulness of Canada's Evergreen National Child and Youth Mental Health Framework (Evergreen) is examined in the development of a Yukon Child and Youth Mental Health and Addictions Framework (CYMHAF). Evergreen content and processes and the reflections of key informants and the research team are analyzed. The findings suggest that national frameworks can play important roles at the program and strategic levels, saving time and money in developing local frameworks, strengthening rigour, and helping to build consensus among local policy-makers.
\end{abstract}

Keywords: child and youth mental health, Yukon, national framework, local policy development, addictions, case study

Gillian Mulvale, DeGroote School of Business, McMaster University; Stanley Kutcher, Department of Psychiatry, Dalhousie University; Glen Randall, DeGroote School of Business, McMaster University; Patricia Wakefield, DeGroote School of Business, McMaster University; Christopher Longo, DeGroote School of Business, McMaster University; Julia Abelson, Clinical Epidemiology and Biostatistics, McMaster University; Marie Fast, Department of Health and Social Services, Yukon Government.

This research was supported by a grant from the Canadian Institutes for Health Research (\#HID-127195). The authors thank Alison Mulvale for excellent design contributions.

Correspondence concerning this article should be addressed to Gillian Mulvale, DeGroote School of Business, McMaster University,1280 Main Street West, DSB 224, Hamilton, ON L8S 4M4; Email: mulvale@mcmaster.ca. 


\section{RÉSUMÉ}

Les documents-cadres nationaux sont souvent affichés comme étant des outils pour le développement de politiques locales, mais on sait peu de choses sur leur efficacité. Dans cette étude de cas, on étudie l'utilité du document-cadre en matière de santé mentale des enfants et des jeunes au Canada, Evergreen, pour le développement d'un cadre en matière de santé mentale, d'alcoolisme et de toxicomanie chez les enfants et les jeunes au Yukon. On y analyse le contenu et les méthodes d'Evergreen et les réflexions de l'équipe de recherche et des informateurs et informatrices clés. Les résultats suggèrent que les documentscadres nationaux peuvent jouer un rôle important aux niveaux de la stratégie et du programme, permettant d'économiser temps et argent dans le développement d'une politique locale, de renforcer la rigueur, et de consolider l'appui des parties intéressées.

Mots clés : santé mentale des enfants et des jeunes, Yukon, cadre national, développement des politiques locales, alcoolisme et toxicomanie, étude de cas

Child and youth mental disorders can place a heavy burden on patients, families, health systems, and society at large, with the negative impacts continuing as the individual becomes an adult. These impacts include risks to social, interpersonal, vocational, and economic outcomes, and workplace productivity, as well as increased risk of suicide, criminal behaviour, and substance abuse (Kutcher, Hampton, \& Wilson, 2010; Kutcher \& McDougall, 2009; Mental Health Commission of Canada, 2012). Although 70\% of all mental disorders can be diagnosed prior to age 25 years (Davidson, 2011; Kessler et al., 2005) and evidence confirms the health and economic benefits of early intervention (Hafner \& Maurer, 2006; Killackey \& Yung, 2007; McGowan, Iqbal, \& Birchwood, 2009; Mental Health Commission of Canada, 2013), only about one-fifth of the approximately one million children and adolescents with a mental disorder in Canada receive any care (Government of Canada, 2006; McEwan, Waddell, \& Barker, 2007; Waddell \& Shepherd, 2002), and many experience further access challenges when they can no longer continue in child and youth services but have continuing service requirements (Davidson, Cappelli, \& Vloet, 2011; Embrett, Randall, Longo, Nguyen, \& Mulvale, 2015; McGorry, 2007; Singh et al., 2010).

The Standing Senate Committee on Social Affairs, Science and Technology called for the creation of the Mental Health Commission of Canada (MHCC) and identified the need for policy attention in the area of child and youth mental health, the "orphan of the orphan" of the health care system (Kirby \& Keon, 2006, p. 155). Child and youth mental health policy development has been identified as a priority to address the complex range of factors, such as inadequate funding, human resource shortages, and silos in services and delivery, that contribute to the gap between need and service use in children's mental health (Kutcher, 2011). One literature review found that only four provinces in Canada had an explicit child and youth mental health policy or plan in place (Kutcher, Hampton, et al., 2010) and that existing plans poorly addressed essential elements identified by the World Health Organization (2005).

The development of child and youth mental health policy in Canada's provinces and territories is complicated by the fact that mental health promotion and treatment services frequently cut across many government departments, agencies, and community organizations, leading to challenges in collaborative and

coordinated delivery. Moreover, these diverse organizations may endorse different values and approaches to 
service delivery. This complexity provides challenges in multiple domains, including funding allocations, priority setting, human resource development, application of standards, and evaluation. The availability of a national child and youth mental health framework may provide a useful template to assist jurisdictions as they work toward addressing these complexities (Kutcher, 2011; Kutcher \& McLuckie, 2013).

National frameworks are often put forward as a guide for provincial and territorial policy-making in Canada, where health system reform reflects a "balancing act between national uniformity driven by federal funding and regional pluralism arising from provincial administrative autonomy" (Naylor, 1999). The limited published research with respect to the role of national health policy frameworks in local policy-making presents conflicting perspectives. Some argue that national or supra-national frameworks can be helpful for achieving consistency in policy development across jurisdictions (Polychroniou, 2005); for example, Tuah, Qureshi, Dhillos, and Majeed (2010) have developed a national framework to be used as a tool to assess the content of local obesity strategies. Others argue that a better approach may be to start with local policies and build toward a national framework (Nanton, 1991). This approach may be particularly helpful when the intent of a national framework is to support the development of common data sets, or to better understand variation in clinical practice across local jurisdictions (O’Leary, Breheny, Reid, Taryn, \& Emergy, 2006).

In 2008, the MHCC sponsored the publication of Evergreen: A Child and Youth Mental Health Framework for Canada (Evergreen) to serve as a resource for policy-makers in Canada when developing provincial and territorial level child and youth mental health care policy and systems (Kutcher \& McDougall, 2009; Kutcher \& McLuckie, 2013; Kutcher, McLuckie, \& Child and Youth Advisory Committee, Mental Health Commission of Canada, 2010). Evergreen is described as a "non-prescriptive document" that "contains all of the ingredients for governments to consider when developing a child and youth policy framework that meets their particular needs and fiscal realities" (Davidson, 2011, p 11). Evergreen was designed as a national framework, to be consistent with the Canada Health Act, that could be interpreted and applied in congruence with federal-provincial-territorial rights and responsibilities (Kutcher \& McLuckie, 2013; Maioni, 2002). Evergreen contains six core values and numerous tactical examples for use in developing child and youth mental health policy within four strategic directions: promotion, prevention, treatment and ongoing care, and research and evaluation (Kutcher \& McLuckie, 2013; Kutcher, McLuckie, et al., 2010). To our knowledge, however, there is no known research that examines how helpful in practice such national health policy frameworks are in informing the development of local (i.e., provincial and territorial) strategies and policies. It has been argued that the utility of national-level strategies and data for local policy-making may be limited because national strategies may lack sensitivity to local conditions that directly affect the health and well-being of residents of the community in question (Mittelmark, 2001). Failure to meet local needs is a particular concern in remote areas, including for Aboriginal populations (Smylie \& Anderson, 2006).

In 2012, the Yukon Department of Health and Social Services partnered with a team of researchers from McMaster and Dalhousie Universities (the research team) in a community-based participatory policy research study (Freudenberg, Rogers, Ritas, \& Nerney, 2005). The objective was to examine the existing service gaps and areas of overlap in child and youth mental health and addictions services and to propose a comprehensive child and youth mental health and addictions framework for Yukon (CYMHAF) that would span mental health, addictions, education, and the broader health and social services systems to promote the mental health of Yukon children, youth, and families and respond to mental health care and treatment 
needs. The research team worked closely with a working group composed of members of the Departments of Health and Social Services and Education, Kwanlin Dun First Nation, and the Council of Yukon First Nations. According to working group members, past efforts within the Department of Health and Social Services to better integrate services for children and youth had always eventually broken down. It was felt that an objective external group who could provide best evidence might help overcome some of the previous obstacles. In addition, the use of the Evergreen framework provided a clear starting point for the process. The working group and the research team adopted Evergreen as a reference point and guide in developing CYMHAF. This created an opportunity to pursue a second objective, which was to investigate how well Evergreen met its goal of facilitating child and youth mental health policy development in Canada at the provincial and territorial level. Here we discuss the findings of the Yukon experience with respect to lessons learned about the role of national frameworks in the development of local child and youth mental health policy in Canada.

\section{METHODS}

We adopted a case study approach (Yin, 2003) to examine the usefulness of a national framework in local policy development. ${ }^{1}$ We defined the case to be "the influence of Evergreen as a national level policy framework on development of CYMHAF at the local policy level." Case study research is suited to this project because it can be used to examine a phenomenon when the boundaries between the phenomenon and its context are not clear and to identify "lessons learned" that can be used to guide practices in other settings (Lincoln \& Guba, 1985).

The overarching research question was: To what extent are national frameworks useful in local policy development? We identified three sub-questions:

1. How was Evergreen used in developing CYMHAF?

2. How did Evergreen and CYMHAF compare in terms of content and development processes?

3. To what extent did Yukon policy-makers and the research team find Evergreen helpful (or not) in developing CYMHAF?

Data were drawn from academic and grey literature on Evergreen and other child and youth mental health frameworks, from input about Evergreen from key informant interviews with Yukon policy-makers, and from reflections of the research team. The McMaster and IWK Research Ethics Boards approved the research, and a Yukon Research License was granted.

Research Question 1: How was Evergreen used in developing CYMHAF? A two-step process was used to answer the first sub-question. First, two members of the research team (GM, JW) reflected individually on how Evergreen was used in developing CYMHAF and subsequently discussed their reflections during several meetings. A map of various points of intersection between Evergreen and CYMHAF was then developed and shared with the rest of the team. Feedback indicated that the rest of the team agreed with this mapping.

Research Question 2: How did Evergreen and CYMHAF compare in terms of content and development processes? To answer the second sub-question, the first and second authors reviewed the academic and grey literature on Evergreen development published since 2010 and identified key themes in the areas of 
stakeholder engagement, generating framework content, and synthesizing content into a policy framework. Evergreen development processes were then compared with CYMHAF processes in each of these theme areas. Evergreen and CYMHAF content were next compared in terms of alignment of values, and whether or not each suggested tactic within Evergreen's four strategic directions was or was not captured within CYMHAF. The comparison of each of these items was carried out by GM, JW, MF, and SK independently. There was complete agreement with respect to values, and 92\% agreement with respect to assessments of tactics (69 of 75 tactics). Differences were discussed until consensus was achieved, and the assessment of common tactics was adjusted accordingly. A visual representation was created that mapped the common tactics pertaining to each strategic direction from Evergreen onto the core components of the Yukon framework to indicate areas of common content, and feedback was obtained from the rest of the research team (CL, GR, PW, JA).

Research Question 3: To what extent did Yukon policy-makers and the research team find Evergreen helpful (or not) in developing CYMHAF? To assess policy-makers' perspectives on the helpfulness of Evergreen in developing CYMHAF, we analyzed transcripts of responses from eight Yukon policymakers to two specific questions concerning Evergreen. These questions were asked at the beginning of the study, prior to the development of the CYMHAF, as part of initial interviews held to understand the Yukon context. The first of the two questions asked participants if they were aware that a national framework, called Evergreen, had been developed in Canada for child and youth mental health. If the participant was aware of Evergreen, the second question asked if the participant thought that Evergreen would be a helpful resource for Yukon in developing the CYMHAF. Responses were analyzed in terms of the following pre-determined themes: statements about prior knowledge of Evergreen, statements about the usefulness of Evergreen in developing CYMHAF, and the participants' stated reasons for their responses.

To assess the perspectives of the research team about the helpfulness of Evergreen in developing CYMHAF, the lead researcher and the research coordinator first prepared a document summarizing their own reflections on Evergreen's usefulness. This document was then reviewed and commented on by the other team members. The input of the full team was especially important in this research to balance the previous experiences of two of the authors with respect to Evergreen's development. One of the authors (SK) led the development of Evergreen on behalf of the Child and Youth Advisory Committee of the Mental Health Commission of Canada, and another author (GM) had served as the interface between the MHCC's National Strategy team and the Evergreen team. The rest of the team had little or no prior knowledge of Evergreen or its development and were able to review the findings from a more neutral perspective.

\section{FINDINGS}

\section{Use of Evergreen in Developing CYMHAF (Research Question \#1)}

The first component of this analysis focuses on research team reflections about how Evergreen was used in developing CYMHAF at the local level. Figure 1 summarizes the points of interface between Evergreen and CYMHAF that were identified over the course of developing the Yukon policy document. The top three boxes in the figure show the activities undertaken during each phase of CYMHAF development (Mulvale et al., 2015). The influence of Evergreen during each of these phases is shown in the bottom boxes of Figure 1. 

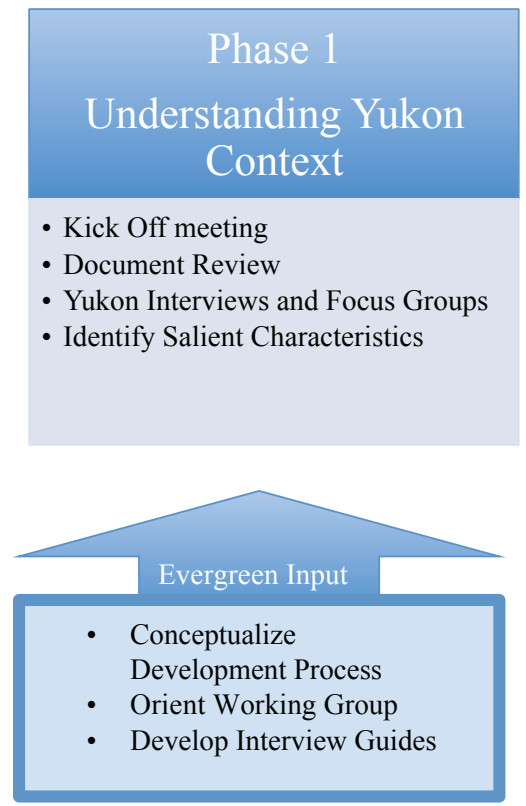

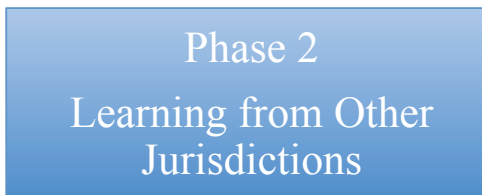

- Update Literature since Evergreen

- Review Frameworks/Programs

- Select Comparator Jurisdictions

- Document Review

- Conduct Comparator Interviews

Figure 1

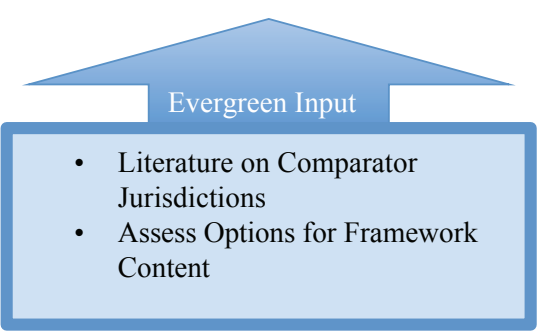

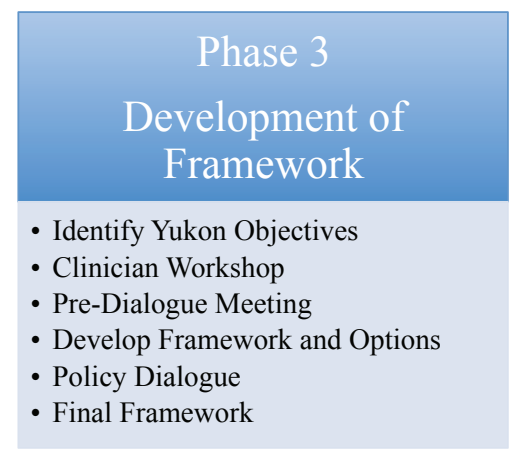

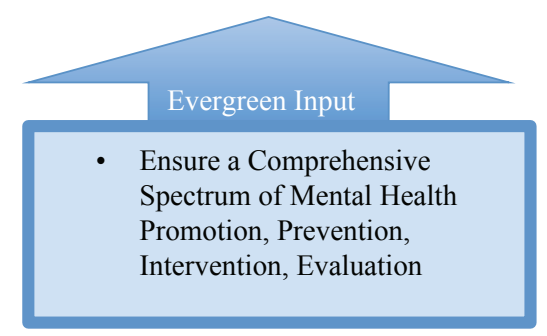

In the first phase of the research, the research team used the Evergreen suggestion to develop a broad stakeholder engagement approach. This approach had two specific goals: (a) gather an in-depth understanding of the local context, and (b) build buy-in to support eventual implementation. The research team conducted numerous face-to-face interviews and focus groups with key informants in Yukon to achieve this broad engagement (see Table 1). These informants included young people with mental disorders, family members, service providers, and policy-makers in Whitehorse and three First Nations communities (Champagne Aishihik, Kwanlin Dun, and Ta'an Kwäch'än). A focus group teleconference was also held with First Nations Health and Social Directors from communities across Yukon.

Evergreen was also used during the first phase as a tool to orient working group members to the project and at the project kick-off meeting held in Whitehorse in May 2013 to stimulate thinking about potential features of a Yukon policy document. Evergreen content also informed the development of key informant and focus group interview guides to ensure that the questions would address what was, and what was not, working well across the full spectrum of promotion, prevention, intervention, and evaluation.

During the second phase of the research, Evergreen's database of academic and policy literature pertaining to child and youth mental health policy was drawn upon and updated for the period 2009 to 2013 . This database was then used to select potential comparator jurisdictions (Alberta, British Columbia, Manitoba, Alberta, Ontario, Alaska, Hawaii, New Zealand, Norway) that shared some of the salient characteristics of 
the Yukon context and had experience in developing child and youth mental health policy frameworks or programming. In each of these jurisdictions, findings from document review and nine key informant interviews (GM and JW) further informed the development of CYMHAF.

In the third phase, Evergreen was used as a reference to ensure the proposed content based on the findings of the first two phases was comprehensive. The goal here was to ensure proposed content was consistent with Evergreen values and inclusive of and balanced in content from each of the four Evergreen strategic directions (promotion, prevention, treatment, and ongoing care; Mulvale et al., 2015).

\section{Table 1}

Yukon Informants by Stakeholder Type and Location

\begin{tabular}{lccccc}
\hline Participant Type & Whitehorse & $\begin{array}{c}\text { CAFN/Haines } \\
\text { Junction }\end{array}$ & KDFN & TKFN & Total \\
\hline Policy-Makers & 15 & 0 & 0 & 0 & 15 \\
Service Providers & 24 & 6 & 2 & 2 & 34 \\
Politician & 1 & 0 & 0 & 0 & 1 \\
First Nations Leaders $^{1}$ & 1 & 1 & 2 & 0 & $4+10^{1}$ \\
Family & 7 & 3 & 3 & 0 & 13 \\
Youth & 10 & 3 & 2 & 0 & 15 \\
Other Agencies & 1 & 5 & 0 & 0 & 6 \\
Total & $\mathbf{5 9}$ & $\mathbf{1 8}$ & $\mathbf{9}$ & $\mathbf{2}$ & $\mathbf{9 8}$ \\
\hline
\end{tabular}

${ }^{1}$ One focus group with 10 First Nations Health and Social Directors from across locations in Yukon.

Abbreviations:

CAFN: Champagne Aishihik First Nation

KDFN: Kwanlin Dun First Nation

TKFN: Ta’an Kwäch'än First Nation

\section{Comparison of Evergreen and CYMHAF Processes and Content (Research Question \#2)}

The second component of this analysis compared Evergreen and CYMHAF in terms of data gathering processes and sources of information (Table 2) as well as content and structure.

Evergreen. An online wiki software (Social Text) was used in developing Evergreen to integrate best available evidence, public input, and expert opinion from across Canada and internationally. The goal was to identify common core values and potential strategic directions for developing child and youth mental health policy. The draft text was reviewed and edited by a large group of national experts across a wide spectrum of mental health and related domains and an international expert child and youth mental health policy committee. The resulting document was validated and further modified with input from youth engagement through a national youth outreach strategy, further stakeholder input at two national conferences, and via broadly publicized online consultations. 
Table 2

Comparing Evergreen and CYMHAF Data Sources and Framework Development Processes

\begin{tabular}{|c|c|}
\hline Evergreen & CYMHAF \\
\hline \multicolumn{2}{|l|}{ Stakeholder Engagement } \\
\hline $\begin{array}{l}\text { - Online wiki for data gathering and drafting } \\
\text { framework } \\
\text { - Drafting, Advisory, International Advisory, Youth } \\
\text { Advisory Committees } \\
\text { - Focus groups at two national conferences } \\
\text { - Online public engagement }\end{array}$ & $\begin{array}{l}\text { - } \quad \text { Yukon key informant interviews and focus groups } \\
\text { - } \quad \text { Modified Delphi process to establish framework } \\
\text { objectives } \\
\text { - } \quad \text { Clinician Workshop } \\
\text { - }\end{array}$ \\
\hline \multicolumn{2}{|l|}{ Literature and Expert Input } \\
\hline $\begin{array}{l}\text { Expert review of best evidence and child and youth } \\
\text { mental health policy documents (academic and } \\
\text { policy literature) } \\
\text { - Input from public, international experts }\end{array}$ & $\begin{array}{ll}\text { - } & \text { Expert review and update of Evergreen database } \\
\text { - } & \text { Input from key informant/focus group interviews } \\
\text { - } & \text { Input from Working Group } \\
\text { - Input from Clinician Workshop }\end{array}$ \\
\hline \multicolumn{2}{|l|}{ Finalizing the Framework } \\
\hline $\begin{array}{l}\text { - } \\
\text { - } \\
\text { - } \\
\text { - } \\
\text { Intergergreen resears of MHCC stafional experts in child and youth mental } \\
\text { health policy }\end{array}$ & $\begin{array}{l}\text { - } \text { Policy Dialogue input } \\
\text { - } \text { Full Research Team } \\
\text { - } \text { Working Group Members }\end{array}$ \\
\hline
\end{tabular}

The core values identified in Evergreen are intended to inform all aspects of child and youth mental health policy development. The Evergreen framework is rooted in a human-rights-based approach that values equity and diversity. Evergreen calls for equal and timely access to information, services, and care that are based on best evidence, are cost-effective, and are matched to people's needs. According to the Evergreen framework, services and care should be coordinated, community-based, and collaborative, and should empower youth and families to be meaningfully engaged in decisions that affect their development. At the same time, Evergreen promotes the creation of social contexts in which young people have the opportunity for healthy mental development.

Evergreen suggests evidence-based tactics within each of its four strategic directions that policymakers can apply depending on the local geo-political, socio-cultural, and fiscal context of each jurisdiction. Examples of tactics include evidence-based mental health awareness programs (promotion), pre- and post-natal identification of at-risk mothers (prevention), training family physicians to provide basic child and youth mental health care in collaboration with specialty services (intervention and ongoing care), and processes for applying research findings in program selection (research and evaluation). The intent is that each jurisdiction will choose the appropriate combination of tactics from each strategic direction that is most applicable to its context and best meets its needs. 
CYMHAF. CYMHAF differed from Evergreen in both its development processes and its intended use at the territorial level. While both Evergreen and CYMHAF were rooted in best evidence and broad stakeholder engagement, CYMHAF was based on traditional research tools (literature reviews, key informant interviews, focus groups, Delphi processes) and integrated knowledge exchange between the research team and working group members throughout the project, and deliberative events rather than online wiki methods. The first draft of CYMHAF content was prepared by the research team and was revised in an iterative manner as input was gathered at three deliberative events held in Whitehorse: a pre-dialogue meeting with working group members and policy-makers from within the Yukon government, a clinician workshop, and a policy dialogue with a range of stakeholders. The final framework was drafted by three members of the research team (GM, SK, JW) and finalized with input from two members of the working group.

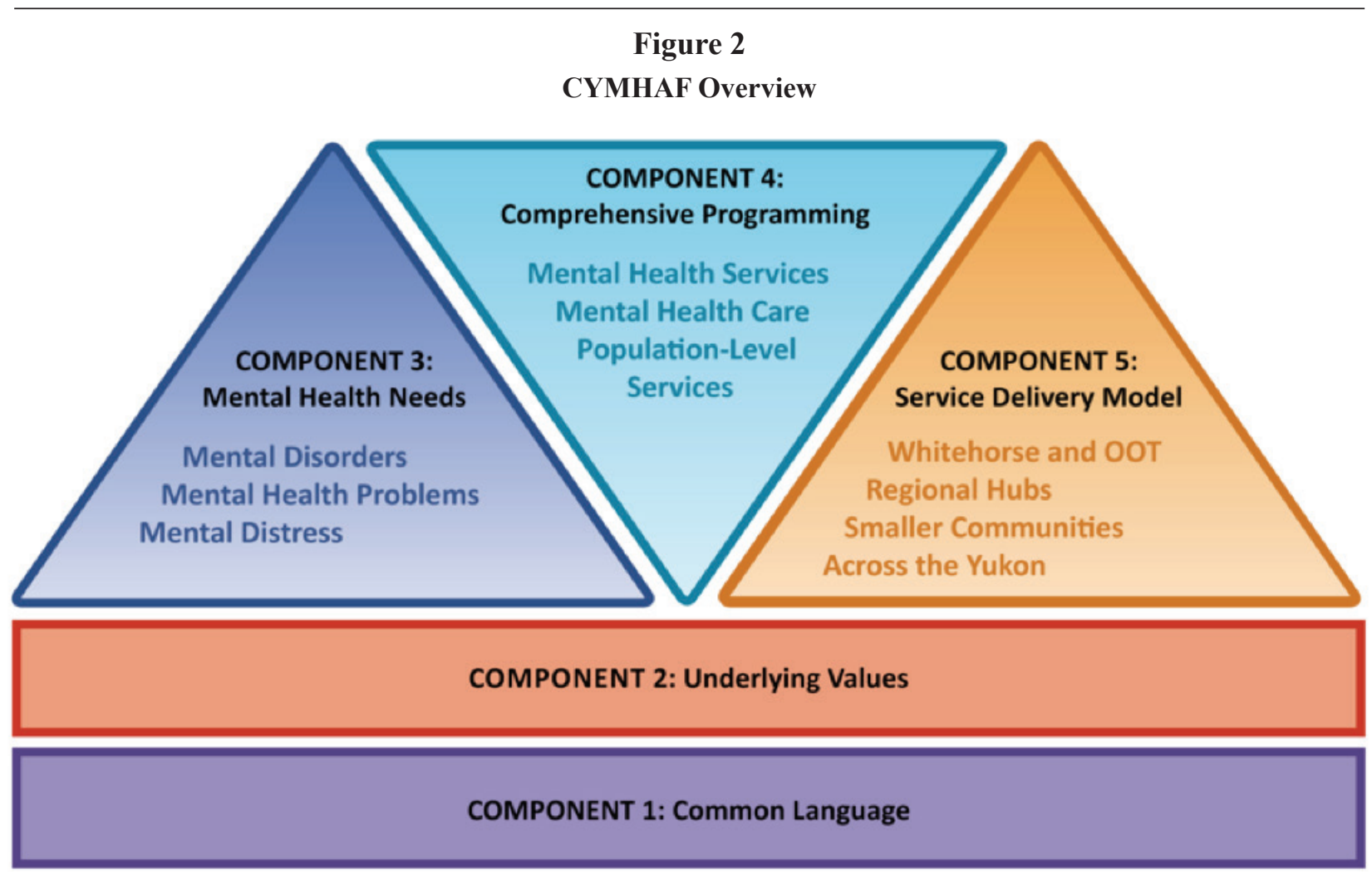

The structure and content of CYMHAF (Figure 2) was also different from Evergreen in order to meet Yukon-specific needs identified by interview participants or Yukon policy-makers using a modified Delphi process. Common language and core values were identified as being critical to enable different departments and agencies to communicate and plan together more effectively. Child and youth mental health needs were positioned as the key driver for the Yukon framework, along with comprehensive programming matched to varying needs delivered through a Cascading Delivery Model (Figure 3). To support this model, existing 
health and human service workers would receive basic child and youth mental health competency training and offer mental health care, identification, and referral in each Yukon community, referring more serious and complex cases to the primary care workers with advanced competencies in regional hubs (Mulvale, Kutcher, \& Winkup, 2014). Primary care workers could refer to specialty mental health providers with enhanced competencies in Whitehorse, with rapid access to specialist consultations outside Yukon when required. All providers would be linked and supported through telehealth capacity, a common electronic health record, and by the creation of a Yukon-specific website to provide information about services in each community, links to child and youth mental health information websites, and online chat capability with mental health experts.

Figure 3

Cascading Service Delivery Model

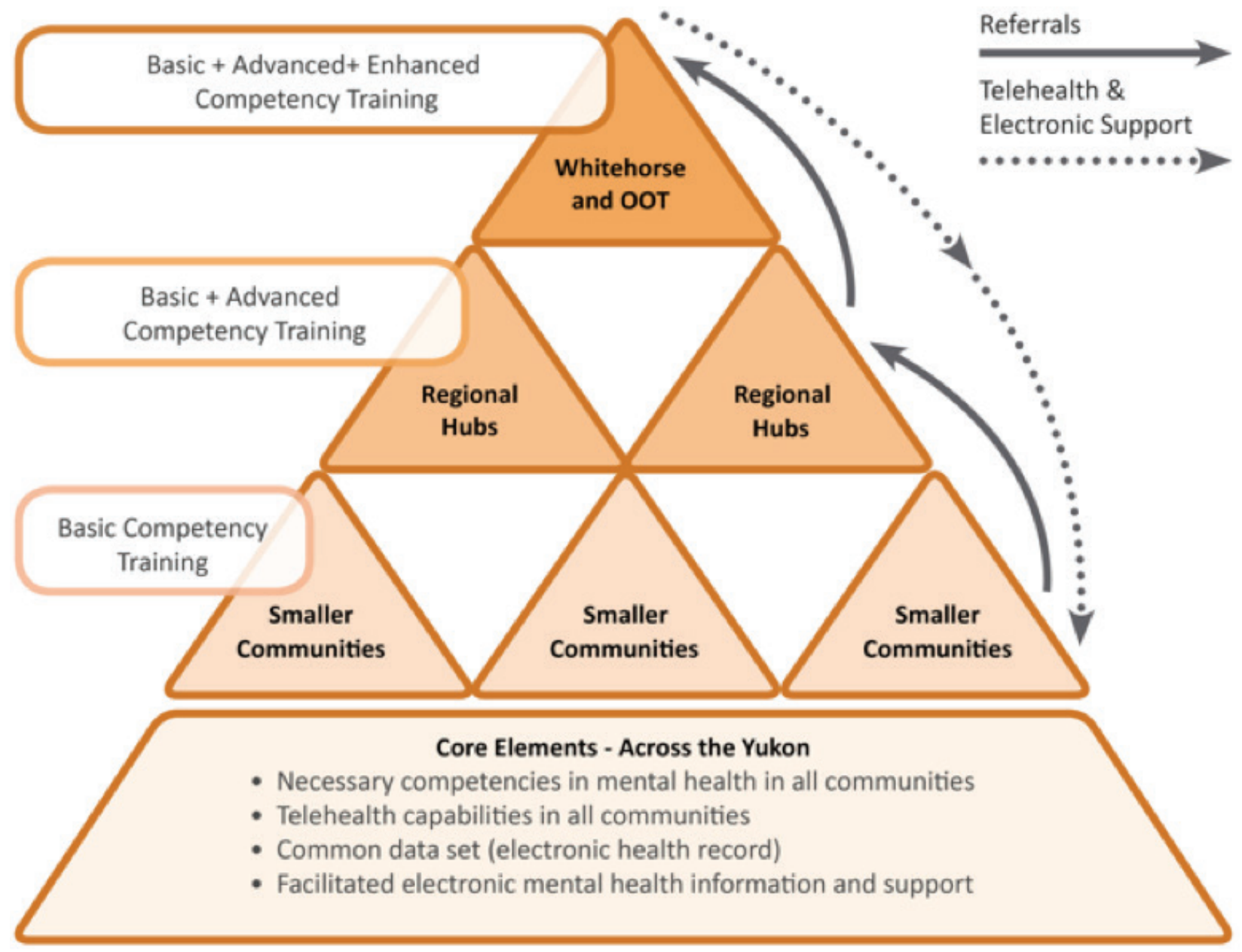


The CYMHAF values were proposed by a subgroup of the working group and subsequently endorsed and expanded to include cultural competency by stakeholders at the policy dialogue (Table 3). There is considerable overlap between the values identified in the Evergreen and CYMHAF frameworks. Both frameworks are evidence-based, are youth- and family-centred, and call for timely access to a set of coordinated services. There are two notable differences in values between the frameworks, however. First, Evergreen is a rights-based framework, which means that it recognizes upholding human rights as a key to improving the lives of young people (Kutcher, McLuckie, et al. 2010). CYMHAF is needs driven, which means that it takes the population mental health needs of children and youth as the starting point for the development of comprehensive programming and of a service delivery model. Second, CYMHAF makes building capacity a value for Yukon, which reflects the current context with respect to addressing and meeting child and youth mental health needs.

Table 3

Comparing Evergreen and CYMAF Values

\begin{tabular}{|l|l|}
\hline Evergreen Values & CYMHAF Values \\
\hline Human Rights & \\
\hline Dignity, Respect, and Diversity & Cultural Competency \\
\hline Best Available Evidence & Evidence-based and Accountable \\
\hline Choice, Opportunity, and Responsibility & Child-, Youth-, and Family-Centred \\
\hline Collaboration, Continuity, and Community & Integrated and Coordinated \\
\hline Access to Information, Programs, and Services & Aligned to Need, Accessible \\
\hline & Build Capacity \\
\hline
\end{tabular}

CYMHAF is consistent with 13 of 19 tactics suggested by Evergreen in the area of promotion, 14 of 19 tactics for prevention, 22 of 29 tactics for intervention and ongoing care, and 5 of 8 tactics for research and evaluation. Some tactics, such as creating sufficient long-term care facilities that specialize in acute care, were not adopted because they were considered to be inappropriate for the Yukon context. In Figure 4 we illustrate the overlap between Evergreen tactics and approaches adopted within the CYMHAF. In the background boxes we summarize the Evergreen tactics for promotion, prevention, intervention, and research and evaluation that were reflected in CYMHAF. The centre "pie pieces" indicate the elements of CYMHAF that operationalize the Evergreen tactics for each strategic direction.

The circular arrows at the centre of the figure are meant to reflect that a few key elements of CYMHAF (e.g., necessary competencies in child and youth mental health, telehealth capacity in every community, a common electronic health record, and a Yukon website) operationalize multiple tactics that span a number 
of strategic directions. For example, the Yukon website is used to increase mental health awareness and literacy and reduce stigma (promotion), offer 24/7 information on where to access services in each community (prevention), and make use of innovative technologies (intervention). Similarly, competency development operationalizes tactics of professional and teacher training in child and youth mental health (promotion), improving rural access (intervention), and developing competencies in evaluation (research and evaluation). In this way, CYMHAF begins the process of integrating the activities of promotion, prevention, treatment, and evaluation that are traditionally carried out by separate government areas and agencies.

\section{Figure 4}

\section{Alignment Between Evergreen Tactics and CYMHAF Elements}
Evergreen Tactics:
CYMHAF Elements:
Evergreen Tactics:

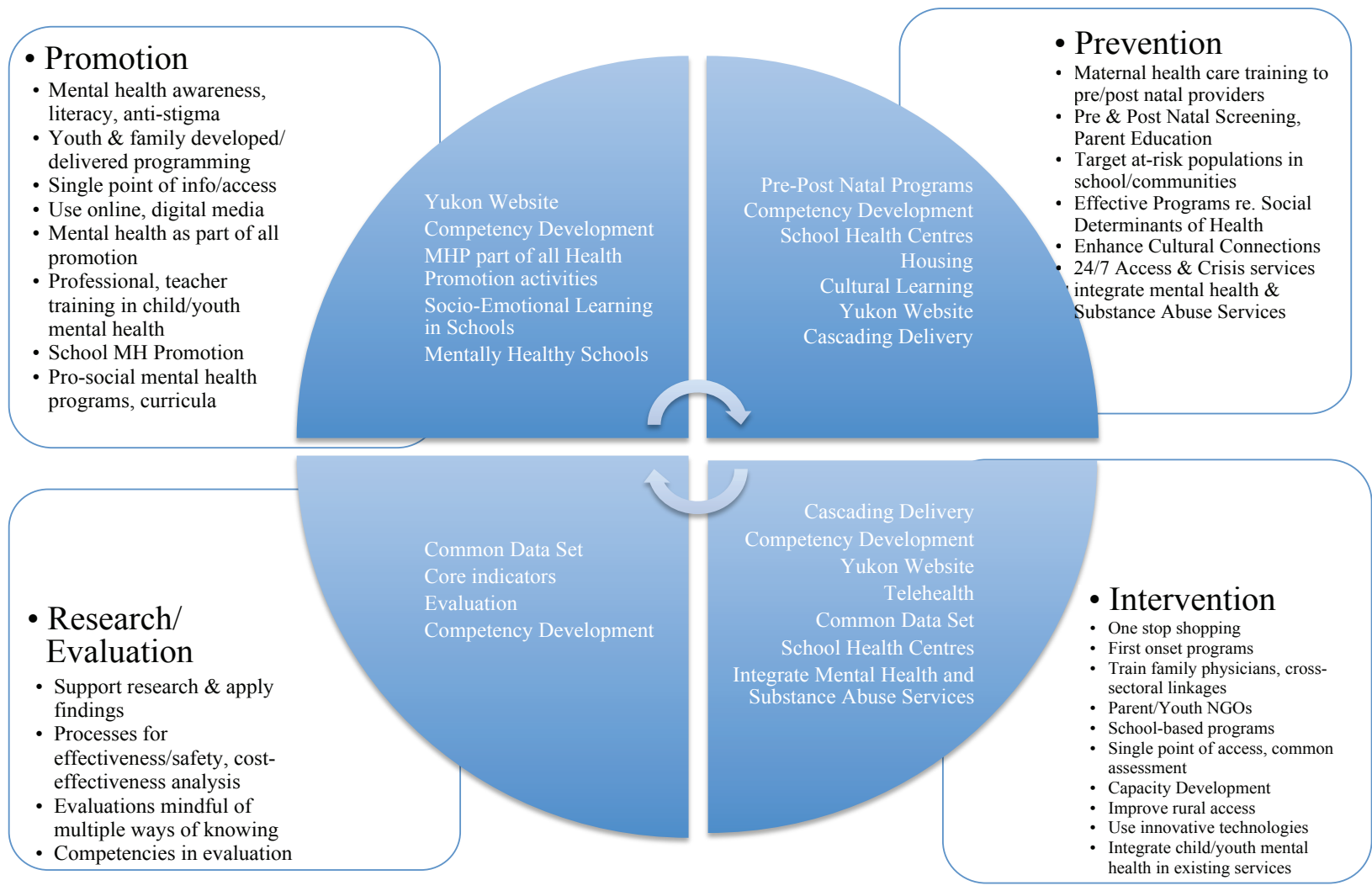

Note: The semi-circular arrows denote that several tactics span multiple strategic directions as part of a comprehensive framework. 


\section{Feedback from Key Informant Interviews on the Helpfulness of Evergreen (Research Question \#3)}

During the phase 1 interviews, policy-maker informants who were familiar with Evergreen were asked if they thought it would be helpful in developing CYMHAF. Most of the respondents did expect that Evergreen would be helpful, albeit in a general sense. These results can be seen in the summary of interview feedback in Table 4. Of the eight policy-makers who commented on Evergreen, only one had no prior knowledge of the framework. Six of the remaining informants found Evergreen to be helpful. One informant found the vision put forward in Evergreen to be consistent with the objective of earlier efforts to improve coordination of services for Yukon children and youth. Another informant found the presentation of values and tactics within each strategic direction useful as a source of ideas for Yukon. Evergreen was also described as being useful as a frame of reference to pull together the various elements of a child and youth mental health system. At the same time, one informant criticized Evergreen for being too all-inclusive: “...everything but the kitchen sink is in there" [PA006], which was not seen as helpful for priority-setting. Finally, one participant thought Evergreen was helpful for the development of a framework but that the larger challenge lay in how to implement it.

\section{DISCUSSION}

This analysis suggests a number of points of intersection between Evergreen and CYMHAF across the three phases of development. A common theme in the key informant interviews and the reflections of the research team was the importance of Evergreen as a reference point in terms of stakeholder engagement and in ensuring comprehensiveness during data gathering and generation of CYMHAF content. The existence of a national framework contributed to enabling the development of a child and youth mental health and addictions framework for Yukon when past efforts had failed to build consensus and were eventually discontinued.

From a practical perspective, Evergreen was seen as a helpful resource that kick-started the process of conceptualizing CYMHAF. Much of the background research on core values and effective strategic directions and tactics had already been completed and was publicly available. This helps busy policy-makers to move quickly into the process and focus on local issues, potentially saving time and resources. Evergreen was also a neutral point of reference in a jurisdiction where differing clinical and philosophical approaches to improving child and youth mental health had previously made it difficult to find common ground.

A lesson learned in earlier efforts is that it is challenging to bring people together from traditionally siloed areas of policy and service delivery at the local level, particularly when no new resources are available and change inevitably means privileging some areas over others. Having a national framework as a neutral reference point was extremely helpful in this situation. It encouraged thinking beyond considerations of turf and power and kept the focus on the needs of Yukon children, youth, and families by stressing a coordinated and collaborative approach.

From a strategic perspective, the existence of a national framework also challenged policy-makers at the local level. Evergreen's emphasis on core values pressured policy-makers to confront the question of whether to give consideration to local values. The decision was made to develop proposed values that 
Table 4

Summary of Key Informant Interview Feedback about Evergreen

\begin{tabular}{|c|c|c|c|}
\hline Informant & $\begin{array}{l}\text { Aware of } \\
\text { Evergreen }\end{array}$ & $\begin{array}{l}\text { Found it } \\
\text { Helpful }\end{array}$ & Comment \\
\hline PA003 & $\mathrm{N}$ & - & $\mathrm{NA}$ \\
\hline PA004 & Y & Y & $\begin{array}{l}\text { "I was involved in a 2-3 year project about } 2 \text { or } 3 \text { years ago, mental } \\
\text { health, Children and Mental Health Services and we were talking about } \\
\text { how we can get collectively together, how we can merge CATS, Child } \\
\text { Abuse Treatment Services with Mental Health Services.... We looked } \\
\text { at how we can assess differently and it kind of all went to the side of the } \\
\text { table, the 'oomph' didn't continue. And then Evergreen was introduced } \\
\text { and I'm looking at it and going, well we were doing this and we could } \\
\text { be here now if we'd only kept it moving... So I like Evergreen, yeah." } \\
\text { [PA004] }\end{array}$ \\
\hline PA005 & Y & $\mathrm{Y}$ & $\begin{array}{l}\text { "There is nothing I would disagree with there. I, I just think that too often } \\
\text { we get the values. Right? We spend a lot of time getting the values and } \\
\text { then we, we lose 'Well, what does this look like in the real world when } \\
\text { I have a child or family at my doorstep.' Or, you know, I have to, um, } \\
\text { interact and coordinate services across different players. What do those } \\
\text { principles mean?" [PA005] }\end{array}$ \\
\hline PA006 & $\mathrm{Y}$ & $\mathrm{N}$ & $\begin{array}{l}\text { “...um, I think everything but the kitchen sink is in there. And it doesn't } \\
\text { really help set priorities. It's, it's too much! It's too much of everything } \\
\text { without an organization that helps you discern what the parts are.” } \\
\text { [PA006] }\end{array}$ \\
\hline PA007 & Y & Y & $\begin{array}{l}\text { “... when I looked at that framework and you know, there's some } \\
\text { excellent stuff in there... I remember reading at the time and just said you } \\
\text { know ah ha, ah ha, yes." [PA007] }\end{array}$ \\
\hline PA008 & $\mathrm{Y}$ & $\mathrm{Y}$ & $\begin{array}{l}\text { "I still think beyond the strategy then you get into the implementation } \\
\text { for it. And at the implementation is really where you have the next } \\
\text { level of dialogue and buy-in and then you start to talk much more about } \\
\text { accountabilities, which is a much more foreign conversation.... This is } \\
\text { basically the beacon and the real work and heavy lifting now is under that } \\
\text { framework ... how do we mobilize and prioritize..." [PA008] }\end{array}$ \\
\hline PA011 & Y & Y & $\begin{array}{l}\text { "...my memory of reading through it was thinking, of course this is just } \\
\text { common sense. This is the range of things that should be out there for } \\
\text { kids, like there's nothing that anybody who isn't in the business can't } \\
\text { agree with. This is just laying it out the way it should exist. So in that way } \\
\text { it probably is a good framework to rub against and ask ourselves, are we } \\
\text { meeting up and where aren't we." [PA011] }\end{array}$ \\
\hline PA012 & $\mathrm{Y}$ & Y & $\begin{array}{l}\text { "I think it is extremely useful and I think probably for me in the context } \\
\text { of the [Yukon], in this context it's a way to pull the thinking together." } \\
\text { [PA012] }\end{array}$ \\
\hline
\end{tabular}


ultimately were well received by stakeholders at the policy dialogue. The Evergreen framework also calls for a coordinated, comprehensive approach across four strategic directions. This encouraged Yukon policymakers to reflect on the extent to which their own services were offered in a coordinated, integrated way, and on how to make better use of existing resources. The Evergreen framework also encourages policy-makers to confront the question of whether and how to involve the public and other stakeholders as contributors to framework development. In Yukon, the decision was made to include the input of children, youth, and family members through interviews and policy dialogue but not to integrate feedback from broader public engagement. Finally, the Evergreen framework advocates for the use of best evidence in decision making, consideration only of options with proven effectiveness and cost-effectiveness, and ongoing evaluation. This emphasis on best evidence added rigour to the selection of elements that were included in CYMHAF.

Based on the analysis contained in this case study and our experience in developing the CYMHAF, we conclude that national frameworks can encourage and support high quality in the development of local policy frameworks, and can help to operationalize aspirational goals and objectives to improve provincial and territorial policy-making. Although each jurisdiction is free to choose how to proceed with respect to the challenges put forward at the national level, the existence of national frameworks can be helpful in ensuring that challenging strategic decisions that may make for a stronger framework in the long run are not side-stepped because of short-run expedience.

Limits on the role that national policy can play in local health policy development in the Canadian context were also confirmed through this case study. First, although many elements of a national framework can be incorporated in a piecemeal way in local policy development, the biggest impact will come if local leaders clearly endorse the national framework and support comprehensive local policy development. Some policy-makers in Yukon had previously considered Evergreen, but its influence was more effective when senior management provided clear support for the research study. Second, jurisdictional responsibilities are such that national frameworks should not be overly prescriptive. The Evergreen approach of stressing the importance of core values that must be considered and a menu of options to operationalize strategic directions appears to have worked well, notwithstanding the criticism that Evergreen was too broad and lacked clear priorities.

A key lesson learned from this experience is that it is important to be precise from the start about what a national framework can and cannot do in order to manage expectations and set a clear understanding of the task at hand for local policy-makers. What a national framework can offer is a frame of reference on which decisions can be made going forward, along with best evidence and suggestions rooted in expert and broad stakeholder support. What it cannot do is the work of priority setting or implementation at the local level, which must be the responsibility of local policy-makers. Otherwise, the national framework would risk pushback on the claim that it is being overly directive in areas of provincial and territorial jurisdiction. An example of this in the Yukon case was the Evergreen value of adopting a human rights approach, which was not viewed as tenable by Yukon officials, whereas a needs-based approach was readily accepted.

There were additional lessons learned about what could have been incorporated into a national framework that would have been helpful at the local level. In the Yukon case, there was a need for education about the definitions of mental health problems and mental illness and about what would constitute an evidence-based 
clinical framework to respond to the full range of needs, from promotion through intervention and evaluation. Evergreen was not explicit on these points and this might be a consideration for its future iterations. This educational role may be important for national frameworks in other content areas as well.

This analysis is subject to several limitations. First, it speaks to national policy development in the specific case of child and youth mental health and addictions in one jurisdiction - Yukon. Although there may be some clear parallels among similar jurisdictions, such as Canada's other territories and northern regions of many other provinces, it is not clear to what extent these lessons would apply in more diverse contexts. This suggests the need to conduct additional research in a range of contrasting jurisdictions to indicate the extent to which lessons learned across a range of contexts may be similar to this case. This could serve as a basis for the development of guidelines for the use of national policy in local policy development. Second, it is difficult to separate out the specific effects of Evergreen from the role of having a research team working in partnership with policy-makers in developing the local framework. Evergreen and the research team members served as neutral reference points when divisions existed across areas within government or other agencies. There was also openness to young people and family members speaking to the research team about what was working well and what was not, which might not have occurred had Yukon government officials conducted the study without an independent partner. The Yukon experience suggests that having a neutral sounding board is extremely important in encouraging participants to provide open feedback. It can also encourage policy-makers to think beyond the impacts on their own staff and departments and consider the broader system impacts. Finally, it is too soon to assess the extent to which having a national framework assists with the implementation of local policies; however, this could be the focus of future research.

\section{CONCLUSION}

This case study suggests that non-prescriptive national health policy frameworks play an important and useful role in local policy development. Such frameworks can save time and resources when developing local frameworks by suggesting processes and content, providing education, and summarizing best evidence. National frameworks can also be helpful strategically by forcing consideration of difficult choices and setting a high-quality bar. They can assist in promoting consistency and coordination in policy areas such as priority setting, allocating funding, human resource development, standard setting, and evaluation. National frameworks can also set a vision for change, be a reference point to assist in decision-making processes going forward, and help to identify common ground that can facilitate coordinated approaches. They cannot set local priorities, however, nor be overly directive about implementation. Transformative change does not happen overnight, and implementation must be equally well thought out to be effective. Nonetheless, through strategic approaches, such as broad stakeholder engagement, national frameworks encourage buy-in and expectations for change that may facilitate implementation.

\section{NOTE}

1. Details of the methods used in the development of CYMHAF are detailed elsewhere (Mulvale et al., 2015). 


\section{REFERENCES}

Davidson, S. (2011). The state of child and youth mental health in Canada: Past problems and future fantasies. Healthcare Quarterly, 14(April), 9-13.

Davidson, S., Cappelli, M., \& Vloet, M. (2011). We've got growing up to do: Transitioning from child and adolescent mental health services to adult mental health services. Ottawa: Ontario Centre of Excellence for Child and Youth Mental Health.

Embrett, M., Randall, G. R., Longo, C., Nguyen, T., \& Mulvale, G. (2015). Effectiveness of health system services and programs for youth to adult transitions in mental health care: A systematic review of academic literature. Administration and Policy in Mental Health and Mental Health Services Research. Advance online publication. doi:10.1007/s10488-015-0638-9

Freudenberg, N., Rogers, M. A., Ritas, C., \& Nerney, M. (2005). Policy analysis and advocacy: An approach to community-based participatory research. In B. A. Israel, E. Eng, A. J. Schulz, and E. A. Parker (Eds.), Methods in community-based participatory resarch for health (pp. 349-370). San Francisco, CA: John Wiley \& Sons.

Government of Canada. (2006). The human face of mental health and mental illness in Canada. Ottawa, ON: Author.

Hafner, H., \& Maurer, K. (2006). Early detection of schizophrenia: Current evidence and future perspectives. World Psychiatry, 5, 130-138.

Kessler, R., Berglunds, P., Demler, O., Jin, R., Merikangas, K., \& Walters, E. (2005). Lifetime prevalence and age-ofonset distributions of DSM-IV disorders in the National Comorbidity Survey Replication. Archives of General Psychiatry, 62(6), 593-602.

Killackey, E., \& Yung, A. (2007). Effectiveness of early intervention in psychosis. Current Opinion in Psychiatry, 20, $121-125$.

Kirby, M. J., \& Keon, W. J. (2006). Out of the shadows at last: Transforming mental health, mental illness and addiction services in Canada. Ottawa, ON: Standing Senate Committee on Social Affairs, Science and Technology.

Kutcher, S. (2011). Facing the challenge of care for child and youth mental health in Canada: A critical commentary, five suggestions for change and a call to action. Healthcare Quarterly, 14(April), 15-21.

Kutcher, S., Hampton, M., \& Wilson, J. (2010). Child and adolescent mental health policy and plans in Canada: An analytical review. The Canadian Journal of Psychiatry, 55(2), 100-107.

Kutcher, S., \& McDougall, A. (2009). Problems with access to adolescent mental health care can lead to dealing with the criminal justice system. Journal of the Canadian Pediatric Society, 14, 12-20.

Kutcher, S., \& McLuckie, A. (2013). Evergreen: Creating a child and youth mental health framework for Canada. Psychiatric Services, 64(5), 479-482. doi:10.1176/appi.ps.201100269

Kutcher, S., McLuckie, A., \& Child and Youth Advisory Committee, Mental Health Commission of Canada. (2010). Evergreen: A child and youth mental health framework for Canada. Calgary, AB: Mental Health Commission of Canada.

Lincoln, Y., \& Guba, E. (1985). Naturalistic inquiry. Beverly Hills, CA: Sage.

Maioni, A. (2002). Roles and responsibilities in healthcare policy (Discussion paper no. 34). Ottawa, ON: Commission on the Future of Health Care in Canada.

McEwan, K., Waddell, C., \& Barker, J. (2007). Bringing children's mental health "Out of the Shadows." Canadian Medical Association Journal, 176(4), 12-20.

McGorry, P. (2007). The specialist youth mental health model: Strengthening the weakest link in the public mental health system. Medical Journal of Australia, 187(7 Suppl), S53-56.

McGowan, S., Iqbal, Z., \& Birchwood, M. (2009). Early interventions in psychosis. In C. Brooker \& J. Repper (Eds.), Mental health: From policy to practice (pp. 137-150). London, UK: Churchill Livingstone Elsevier.

Mental Health Commission of Canada. (2012). Changing directions, changing lives: The mental health strategy for Canada. Calgary, AB: Mental Health Commission of Canada.

Mental Health Commission of Canada. (2013). Making the case for investing in mental health in Canada. Retrieved from http://www.mentalhealthcommission.ca/English/node/5020

Mittelmark, M. B. (2001). Promoting social responsibility for health: Health impact assessment and healthy public policy at the community level. Health Promotion International, 16(3), 269-274. doi:10.1093/heapro/16.3.269 
Mulvale, G., Kutcher, S., \& Winkup, J. (2014). A child and youth mental health and addictions framework for the Yukon. Hamilton, ON: McMaster University. Retrieved from http://www.degroote.mcmaster.ca/files/2012/08/ Yukon-Framework-Final-June11.pdf

Mulvale, G., Kutcher, S., Randall, G., Wakefield, P., Longo, C., Abelson, J., ... Wishart, J. (2015). A child and youth mental health and addictions framework for the Yukon: Final research report. Retrieved from http://www.degroote. mcmaster.ca/files/2012/08/FINAL-YUKON-CHILD-AND-YOUTH-RESEARCH-REPORT-reduced-size.pdf

Nanton, P. (1991). National frameworks and the implementation of local policies: Is a European model of integration identifiable? Policy \& Politics, 19(3), 191-198.

Naylor, C. D. (1999). Health care in Canada: Incrementalism under fiscal duress. Health Affairs, 18(3), 9-26. doi:10.1377/ hlthaff.18.3.9

O’Leary, P., Breheny, N., Reid, G., Taryn, C., \& Emergy, J. (2006). Regional variations in prenatal screening across Australia: Stepping towards a national policy framework. Australian and New Zealand Journal of Obstetrics and Gynaecology, 46, 427-432.

Polychroniou, C. G. (2005). A normative approach for the harmonization of national policies to supra-national frameworks with reference to Greece and the European Union. European Planning Studies, 13(5), 773-791.

Singh, S., Paul, M., Ford, T., Kramer, T., McLaren, S., Hovish, K., ... White, S. (2010). Process, outcome and experience of transition from child to adult mental healthcare: Multiperspective study. British Journal of Psychiatry, 197(4), 305-312.

Smylie, J., \& Anderson, M. (2006). Understanding the health of Indigenous peoples in Canada: Key methodological and conceptual challenges. Canadian Medical Association Journal, 175(6), 602-612.

Tuah, N., Qureshi, S., Dhillos, W., \& Majeed, A. (2010). Development and application of the Imperial College Obesity Strategy Assessment Framework for analysing local obesity strategies. Primary Health Care Research \& Development, 12(2), 83-94.

Waddell, C., \& Shepherd, C. (2002). Prevalence of mental disorders in children and youth: A research update prepared for the Ministry of Children and Family Development. Vancouver: University of British Columbia.

World Health Organization. (2005). Mental health policy and service guidance package: Child and adolescent mental health policies and plans. Geneva, Switzerland: Author.

Yin, R. (2003). Case study research design and methods (Third ed. Vol. 5). Thousand Oaks, CA: Sage. 